\title{
Aberrant Activation of Atypical Protein Kinase C in Carbon Tetrachloride-Induced Oxidative Stress Provokes a Disturbance of Cell Polarity and Sealing of Bile Canalicular Lumen
}

\author{
Yosuke Horikoshi, ${ }^{* \dagger}$ Kanae Kitatani, ${ }^{\ddagger}$ Kentaro Toriumi, ${ }^{*}$ Nahoko Fukunishi, ${ }^{\S}$ Yoshiko Itoh,, Naoya Nakamura, ${ }^{*}$ Shigeo Ohno, \\ Tatsuya Matsura, ${ }^{\dagger}$ and Susumu Takekoshi ${ }^{* \ddagger}$ \\ From the Department of Pathology, ${ }^{*}$ and the Division of Host Defense Mechanism, ${ }^{\ddagger}$ Department of Cell Biology, Tokai University School of Medicine, \\ Isehara; the Division of Medical Biochemistry, ${ }^{\dagger}$ Department of Pathophysiological and Therapeutic Science, Tottori University Faculty of Medicine, Yonago; \\ the Support Center for Medical Research and Education, ${ }^{\S}$ Tokai University, Isehara; and the Department of Molecular Biology, ${ }^{\natural}$ Yokohama City University \\ Graduate School of Medical Science, Yokohama, Japan
}

Accepted for publication

December 11, 2014.

Address correspondence to Susumu Takekoshi, Ph.D., Division of Host Defense Mechanism, Department of Cell Biology, Tokai University School of Medicine, 143 Shimokasuya, Isehara, Kanagawa 259-1193. E-mail: takekos@is.icc.u-tokai.ac.jp.

\begin{abstract}
Polarized hepatocytes contain tight junctions (TJs), which are among the most important junctions for sealing the bile canalicular lumen from the sinusoidal space. Alterations in TJs are implicated in chronic cholestatic liver diseases, such as primary biliary cirrhosis and primary sclerosing cholangitis, which have lipid peroxidation marker elevations or antioxidant vitamin decreases. However, the effect of oxidative stress on hepatocyte polarity or liver morphology is unknown. We found that carbon tetrachloride $\left(\mathrm{CCl}_{4}\right)_{-}$ induced oxidative stress resulted in disassembly of TJs. Ultrastructural analysis revealed disruption in TJs, Golgi morphology, and expansion of the bile canalicular lumen size in $\mathrm{CCl}_{4}$-treated hepatocytes. The Par complex [Par-3-atypical protein kinase $\mathrm{C}(\mathrm{aPKC})$ and Par-6 ternary complex] regulates TJs and lumen formation, and the Par-3-aPKC complex formation was inhibited by $\mathrm{CCl}_{4}$ treatment. Moreover, the antioxidant compound vitamin E prohibited a $\mathrm{CCl}_{4}$-induced disturbance in TJs and Par-3-aPKC complex formation. aPKC phosphorylates Par-3 and down-regulates its own affinity with Par-3. Importantly, aPKC kinase activity and Par-3 phosphorylation were significantly increased in $\mathrm{CCl}_{4}$-treated rat livers. These results indicate that the Par-3-aPKC complex plays a crucial role in the maintenance of hepatocyte polarity and sealing of the bile canalicular lumen. Our findings suggest that bile canalicular lumen expansion might explain the presence of cholestasis in patients with primary biliary cirrhosis and primary sclerosing cholangitis. (Am J Pathol 2015, 185: 958-968; http://dx.doi.org/10.1016/j.ajpath.2014.12.015)
\end{abstract}

Polarized hepatocytes develop junctional structures that contain adherens junctions (AJs), tight junctions (TJs), and gap junctions. TJs are among the most important functional structures for sealing the bile canalicular apical lumen from the sinusoidal space. ${ }^{1,2}$ Dysfunction of $\mathrm{TJ}$ s and distinct biliary transport systems are associated with primary causes of biliary cholestasis and sclerosing cholangitis. ${ }^{1}$

The polarity regulating protein complex, the Par complex, comprises partitioning defective-3 (Par-3), partitioning defective-6 (Par-6), and atypical protein kinase $\mathrm{C}$ (aPKC). ${ }^{6,7}$ Accumulating evidence has established that the Par complex is essential for the maturation of epithelia-specific junction structures, such as AJs and TJs. ${ }^{6,7}$ Most polarized cells have specialized organization of actin and microtubule cytoskeletons that have several roles in cell polarity and the vesicle transport system (vesicle trafficking) because it is regulated by the Par complex. ${ }^{8,9}$ Knockdown of Par-3 induced a disruption of apical lumen formation and evoked microvillus inclusion bodies that were similar to the phenotype of inflammatory bowel disease and microvillus inclusion disease. ${ }^{8,10}$ A recent report revealed

Supported in part by a Grant-in-Aid for Science Research (grant 20590385), a Grant-in-Aid for Young Scientists (grant 23790379) from the Japan Society for Promotion of Science (S.T. and Y.H.), and Tokai University School of Medicine research aid from 2009 to 2011 (Y.H.).

Disclosures: None declared. 
that knockdown of Par-3 prevented de novo bile canaliculus formation in an in vitro culture system. ${ }^{11}$ Selective depletion of $a P K C \lambda$ in mouse podocytes results in the disassembly of intercellular junctions (slit diaphragms) and focal segmental glomerulosclerosis (FSGS). ${ }^{12}$ FSGS pathogenic pathways may involve oxidative stress and inflammation associated with mononuclear leukocyte recruitment. ${ }^{13}$ However, the molecular mechanisms underlying the roles of the Par complex in oxidative stress and oxidative stress-mediated cell injury remain to be clarified.

We found that carbon tetrachloride $\left(\mathrm{CCl}_{4}\right)$-induced oxidative stress resulted in the disassembly of TJs and the translocation of Par-3 and aPKC from TJs to cytoplasm. Defects in the interaction between Par-3 and aPKC lead to the disassembly of junctional structures and also to the loss of Golgi apparatus and orientation in rat livers and were implicated in the disturbance of apical-basal cell polarity. In addition, biochemical analyses revealed that Par-3-aPKC interaction was inhibited by $\mathrm{CCl}_{4}$ treatment. aPKC phosphorylates Ser827 within the aPKC-binding region of Par-3 and thereby down-regulates its own affinity for Par- $3 .{ }^{14} \mathrm{We}$ found that aPKC kinase activity and the phosphorylation level of Ser827 in Par-3 increased significantly. The present results indicated that oxidative stress induced a disturbance of hepatocyte polarity through aberrant activation of aPKC, resulting in the phosphorylation of Ser827 of Par-3 and dissociation of its interaction.

\section{Materials and Methods}

\section{Antibodies}

All antibodies were purchased from commercial sources as follows: anti-ZO-1, anti-occludin, and anti-claudin-1 rabbit polyclonal antibodies (Life Technologies, Carlsbad, CA); anti-E-cadherin (Clone 36), anti-aPKCl (Clone 23), and anti-GM130 (Clone 14) mouse monoclonal antibodies (BD Biosciences, San Jose, CA); anti-aPKC (C20) and anti- $\beta$ catenin (H-102) rabbit polyclonal antibody, anti-ZO-1 (R40.76) rat monoclonal antibody, anti-TGN38 (B-6), and anti-glyceraldehyde-3-phosphate dehydrogenase (6C5) mouse monoclonal antibody, and mouse, rabbit, and rat control IgGs (Santa Cruz Biotechnology, Santa Cruz, CA); antiphospho-aPKC $\zeta / \lambda$ Thr410/403, anti-phospho-Akt Ser473 or Thr308, and anti-Akt rabbit monoclonal antibodies (Cell Signaling Technology, Beverly, MA); anti-P-glycoprotein (JSB-1) mouse monoclonal antibody (Abcam Ltd, Cambridge, UK); anti- $\beta$-actin mouse monoclonal antibody (AC15; SigmaAldrich, Tokyo, Japan); anti-4-hydroxy-2-nonenal (HNE) mouse monoclonal antibody (HNEJ-2; JAICA, Shizuoka, Japan); TOPRO-3, Alexa Fluor 488-, Alexa Fluor 594-, and Alexa Fluor 647-conjugated secondary antibodies (Life Technologies); and horseradish peroxidase-conjugated secondary antibodies (GE Healthcare Bio-Sciences, Piscataway, NJ). Anti-phospho-Par-3 Ser827 rabbit polyclonal antibody (pAb) was raised against the synthesized phosphopeptide [CGFGRQS(-P)MSEKR]. ${ }^{14}$ The phospho-specific mouse monoclonal antibody against serine 653 of human Llg12 was raised against a phospho-peptide [KSLRES(-P) FRKLR] and was described previously. ${ }^{15}$

\section{Experimental Model}

Male Wistar rats (300 g) were injected subcutaneously with an acute hepatotoxic dose of $\mathrm{CCl}_{4}$ (1:1 with corn oil, $1.5 \mathrm{~mL} /$ $\mathrm{kg}$ body weight, Sigma-Aldrich). Rats receiving corn oil alone were used as controls. Animals were euthanized at 2 and 6 hours after $\mathrm{CCl}_{4}$ administration $(n=7)$. In some experiments, i.p. vitamin E (DL- $\alpha$-tocopherol acetate, $100 \mathrm{mg}$ / kg body weight, Sigma-Aldrich) was administered 24 hours before $\mathrm{CCl}_{4}$ administration, and animals were euthanized 6 hours after $\mathrm{CCl}_{4}(n=3)$. The livers were removed from anesthetized rats and weighed, snap-frozen in liquid nitrogen, and kept at $-80^{\circ} \mathrm{C}$ for biochemical analysis. A portion of the liver was immediately fixed in formalin for histologic analyses. All animal experiments were conducted in accordance with the guidelines for proper conduct of animal experiments (Science Council of Japan), and all protocols were approved by our institutional review board.

\section{Histologic Analysis and Immunofluorescence Microscopy}

Ten percent formalin-fixed, paraffin-embedded liver sections were used for hematoxylin and eosin staining, and 4\% paraformaldehyde-fixed frozen sections were used for Oil red $\mathrm{O}$ staining. A portion of liver tissue was fixed by immersion in Mildform 10N (Wako Pure Chemical Industries, Ltd., Osaka, Japan) overnight. Paraffin-embedded sections $(4 \mu \mathrm{m})$ were deparaffinized in xylene and rehydrated in graded series of ethanol. Endogenous peroxidase activity was blocked with $0.3 \%$ hydrogen peroxide in methanol for 30 minutes. For immunostaining, sections were autoclaved at $121^{\circ} \mathrm{C}$ for $15 \mathrm{mi}-$ nutes in $1 \mathrm{mmol} / \mathrm{L}$ EDTA (pH 8.0). After blocking with 10\% calf serum, the sections were incubated overnight at $4^{\circ} \mathrm{C}$ with primary antibodies. The secondary antibodies used were Alexa Fluor 488-, 594-, or 647-conjugated goat antibodies against rabbit, mouse, or rat IgG. Cell nuclei were stained with TOPRO3. After immunostaining, the sections were removed from the phosphate-buffered saline wash, dipped briefly in distilled water, treated with copper(II) sulfate (Sigma-Aldrich) in ammonium acetate buffer $\left(50 \mathrm{mmol} / \mathrm{L} \mathrm{CH}_{3} \mathrm{COONH}_{4}, \mathrm{pH}\right.$ 5.0) for 2 hours, redipped briefly in distilled water, and returned to phosphate-buffered saline. ${ }^{16}$ These sections were mounted with phosphate-buffered saline that contained $90 \%$ (wt/vol) glycerol and $0.0125 \%$ (wt/vol) DABCO (Sigma-Aldrich) and examined using a Zeiss LSM510 Meta confocal microscope (Carl Zeiss, Jena, Germany).

\section{Immunohistochemistry}

Antibodies were from the following sources and used as indicated: anti-HNE, anti-ZO-1, anti-Par-3, anti-TGN38, 


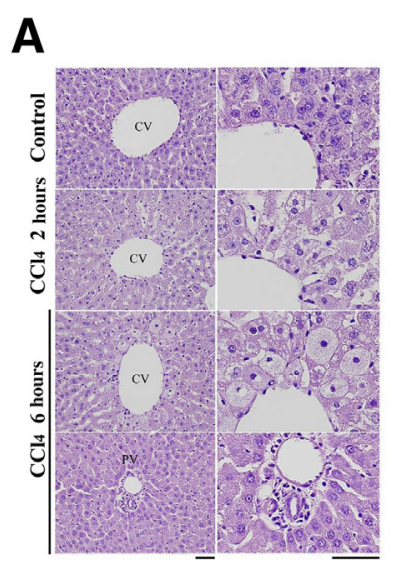

B
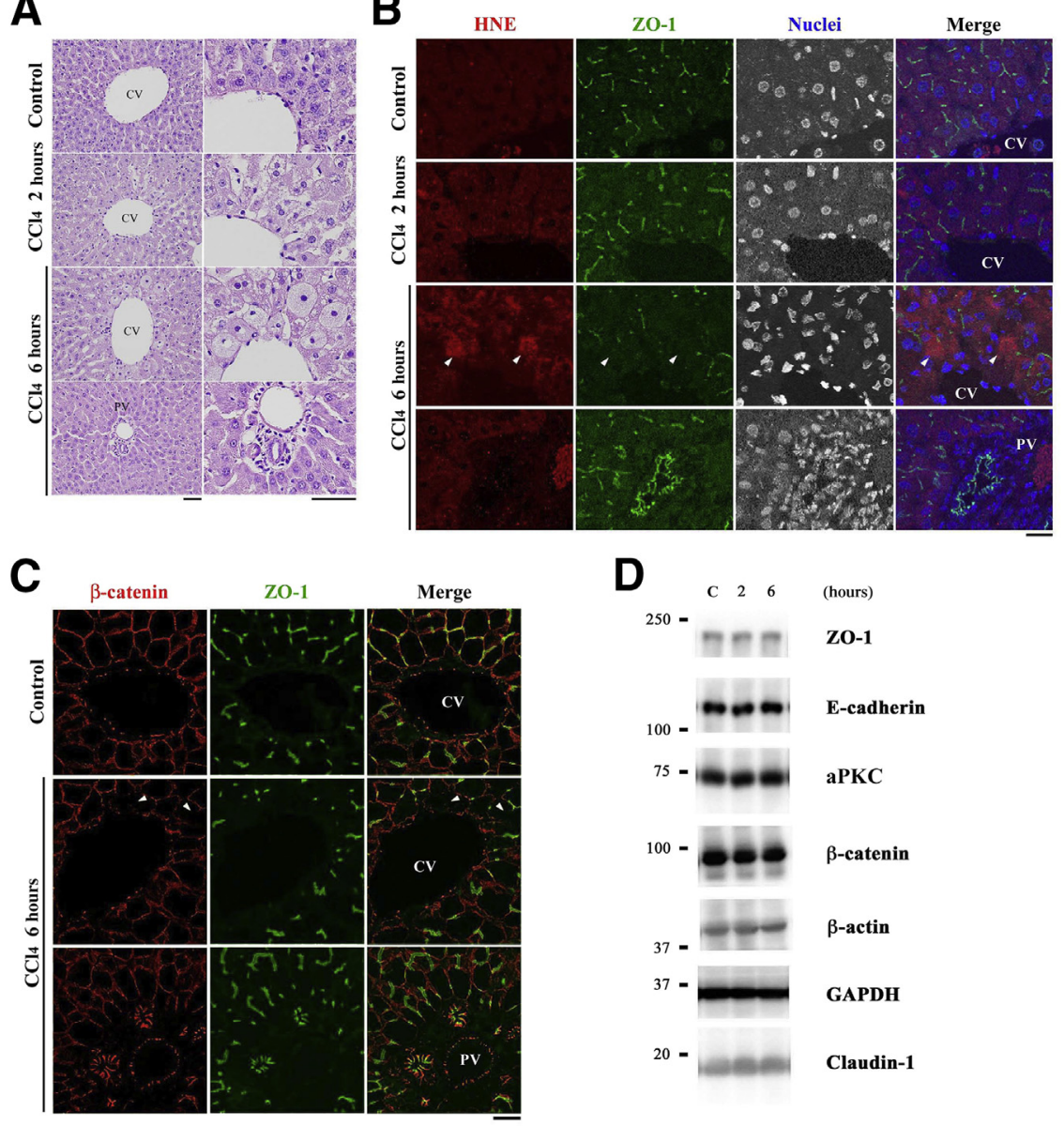

E
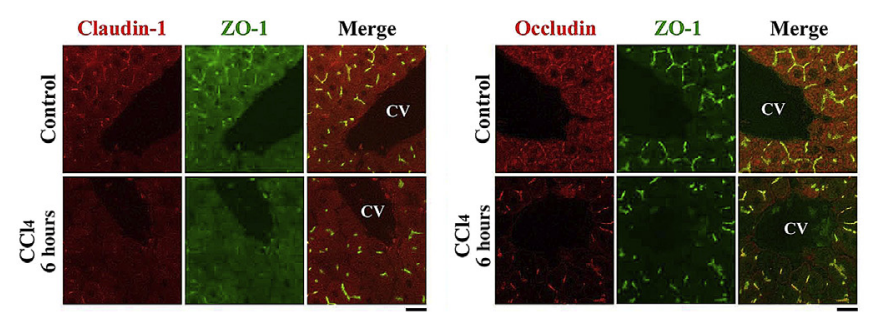

Figure 1 Carbon tetrachloride $\left(\mathrm{CCl}_{4}\right)^{-}$ mediated oxidative stress results in a disturbance of the distribution of junctional complex proteins in rat hepatocytes. A: Rat livers stained with hematoxylin and eosin at control (0 hours), 2 hours, and 6 hours after $\mathrm{CCl}_{4}$ treatment. B: Control or $\mathrm{CCl}_{4}$-treated (2 and 6 hours) livers were immunostained for anti-4-hydroxy-2-nonenal (HNE) (red), Z0-1 (green), and nuclei (blue). Arrowheads indicate HNE-positive cells. C: Livers were fixed and stained for $\beta$-catenin (red) and Z0-1 (green). Arrows indicate disrupted $\beta$-catenin (red) with Z0-1 (green) signal at cell-cell contact sites. D: Western blot data reveal the expression levels of the TJ proteins Z0-1 and claudin-1, the adherens junctions and cytoskeletal proteins E-cadherin and $\beta$-catenin, the polarity protein atypical protein kinase $\mathrm{C}(\mathrm{aPKC})$, and the internal controls $\beta$-actin andglyceraldehyde-3-phosphate dehydrogenase (GAPDH). E: Livers were immunostained for claudin-1 (red) (left) or occludin (red) (right) and Z0-1 (green). Confocal stack images are shown in B, C, and E. Scale bars: $50 \mu \mathrm{m}$ (A); $20 \mu \mathrm{m}$ (B, C, and E). CV, centrilobular vein; $\mathrm{PV}$, portal vein. and anti-P-glycoprotein. Slides were treated with $100 \%$ methanol and $3 \% \mathrm{H}_{2} \mathrm{O}_{2}$ at room temperature for 30 minutes to reduce endogenous peroxidase activity. The samples were rinsed in water and subjected to antigen retrieval at $121^{\circ} \mathrm{C}$ by autoclave for 10 minutes in $10 \mathrm{mmol} / \mathrm{L}$ Tris- $\mathrm{HCl}(\mathrm{pH} 10.0)$ for P-glycoprotein. To stain ZO-1, Par-3, and TGN38, the sections were autoclaved at $121^{\circ} \mathrm{C}$ for 10 minutes in $1 \mathrm{mmol} / \mathrm{L}$ EDTA (pH 8.0). For HNE, sections were autoclaved at $121^{\circ} \mathrm{C}$ for 10 minutes in $10 \mathrm{mmol} / \mathrm{L}$ citrate buffer ( $\mathrm{pH} \mathrm{6.0)}$ ). After blocking for 30 minutes with $5 \%$ normal calf serum, the sections were incubated overnight at $4^{\circ} \mathrm{C}$ with primary antibodies. The labeled secondary antibodies were visualized using a HistoFine kit (Nichirei, Tokyo, Japan), followed by 3,3'-diaminobenzidine reaction. Finally, the sections were counterstained with hematoxylin and observed by AX71 microscopy (Olympus, Tokyo, Japan).

\section{Immunoprecipitation and in Vitro Protein Kinase} Assays

Rat livers were suspended in lysis buffer and were subjected to immunoprecipitation with $1.5 \mu \mathrm{g}$ of antibody. For in vitro kinase assay, aPKC was immunoprecipitated with anti-aPKC (C20) antibody. ${ }^{15}$ The immunoprecipitates in $40 \mu \mathrm{L}$ of phosphorylation buffer were preincubated with $2 \mu \mathrm{g}$ of glutathione $S$-transferase fused to amino acids 633 to 666 of human Llgl2 purified protein for 20 minutes on ice. The phosphorylation reaction was started by adding a substrate mix that contained $40 \mu \mathrm{mol} / \mathrm{L}$ ATP. After 30 minutes at $30^{\circ} \mathrm{C}$, the reaction was stopped by adding SDS sample buffer. The products were subjected to SDS-PAGE, followed by Western blotting as described previously. ${ }^{15}$ 


\section{Electron Microscopy}

Rat livers were fixed with $2.5 \%$ glutaraldehyde in $0.1 \mathrm{~mol} / \mathrm{L}$ phosphate buffer ( $\mathrm{pH} 7.4)$ overnight at $4^{\circ} \mathrm{C}$ and then postfixed with $1 \% \mathrm{OsO}_{4}$ in the same buffer for 90 minutes at room temperature $(n=7)$. The samples were rinsed with distilled water, stained with $0.5 \%$ aqueous uranyl acetate, and dehydrated with ethanol. In all, 60- to 90-nm ultrathin sections were examined with a JEM1400 transmission electron microscope (JEOL Ltd., Tokyo, Japan) operated at an accelerating voltage of $80 \mathrm{kV}$. Ultrathin sections $(60$ to $90 \mathrm{~nm}$ ) were cut from 2 to 5 tissue blocks per animal, and the canalicular lumen was measured on $>30$ sections from each animal.

\section{Statistical Analysis}

Values are expressed as means $\pm \mathrm{SD}$. Differences were analyzed by Student's $t$-test or Welch's $t$-test, and statistical significance was considered when $P<0.05$.

\section{Results}

\section{Oxidative Stress Induces Disruption of Cell-Cell Junctions in Hepatocytes}

$\mathrm{CCl}_{4}$ induces a phenotype similar to hepatic steatosis and cirrhosis in the liver. ${ }^{17,18}$ The levels of lipid peroxidation are increased in $\mathrm{CCl}_{4}$-treated rat liver. ${ }^{17}$ Fatty degeneration was observed in $\mathrm{CCl}_{4}$-treated hepatocytes facing central veins but not in periportal areas (Figure 1A and Supplemental Figure S1). To elucidate the effect of $\mathrm{CCl}_{4}$ on junctional structures in hepatocytes, we analyzed TJs and AJs at 2 and 6 hours after $\mathrm{CCl}_{4}$ treatment. The centrilobular region of the liver is most susceptible to chemical toxins that are catalyzed by cytochrome P450. ${ }^{18,19}$ The TJ components, ZO-1, claudin-1, and occludin, were localized in the vicinity of bile canaliculi, where TJ structures were linearly stained in normal rat liver (Figure 1). In contrast, at 6 hours after $\mathrm{CCl}_{4}$ treatment of livers, the localization of these proteins had markedly disappeared from TJ structures (Figure 1, B, C, and $\mathrm{E}$ ). These defects were observed even at 2 hours of $\mathrm{CCl}_{4}$ administration, but the effects were stronger at 6 hours of $\mathrm{CCl}_{4}$ treatment (Figure 1B and Supplemental Figure S2). On the other hand, the $\mathrm{AJ}$ component, $\beta$-catenin, was distributed at cell-cell contact sites by $\mathrm{CCl}_{4}$ treatment (Figure 1C). Both $\mathrm{TJ}$ and $\mathrm{AJ}$ protein expression levels were not changed by $\mathrm{CCl}_{4}$ treatment (Figure 1D). HNE, one of the major final products of lipid peroxidation, has established cytotoxicity. ${ }^{20}$ Double-label immunofluorescence analysis revealed that HNE signals were observed in ZO-1-negative hepatocytes in $\mathrm{CCl}_{4}$-treated rats (Figure $1 \mathrm{~B}$ and Supplemental Figure $\mathrm{S} 1 \mathrm{~A})$. However, in the $\mathrm{CCl}_{4}$-treated rats, $\mathrm{HNE}$ was not detected in the portal area (Supplemental Figure S1).

Most human cholestatic liver disorders are associated with profound deterioration of the barrier function of

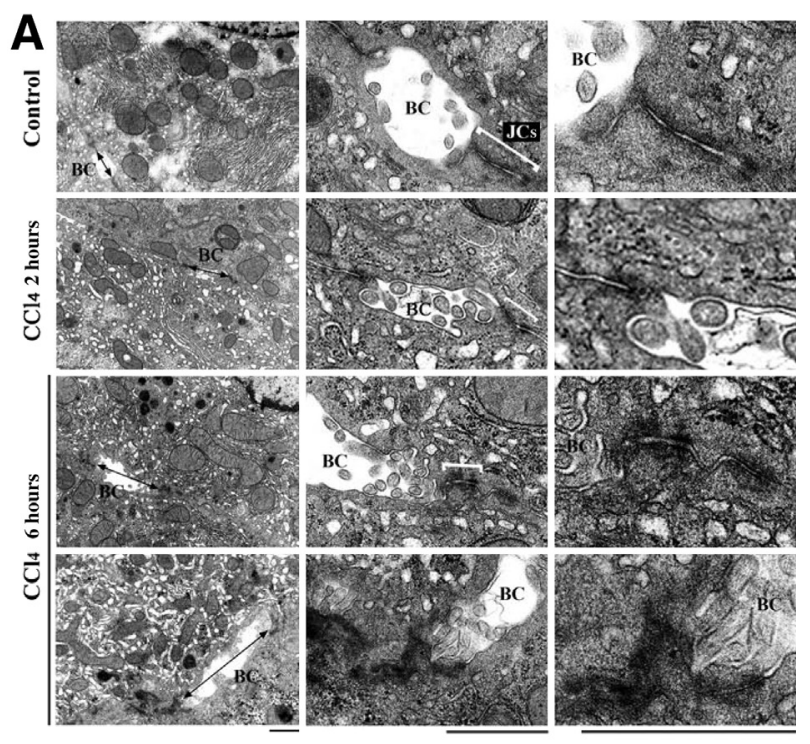

B

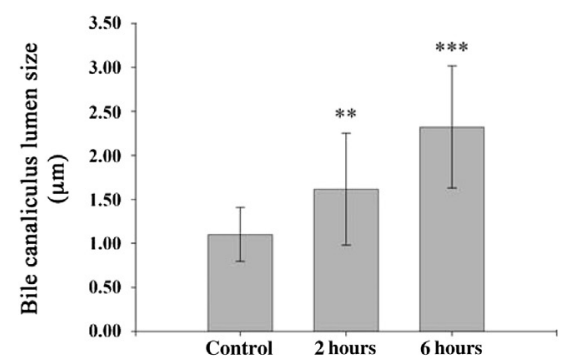

Figure 2 Defects in junctional structures and bile canalicular lumen morphology as observed in carbon tetrachloride $\left(\mathrm{CCl}_{4}\right)$-treated hepatocytes. A: Transmission electron micrographs of control ( 0 hours) and $\mathrm{CCl}_{4}$-treated (2 and 6 hours) rat livers were fixed and sectioned. The lumen of the bile canaliculus (BC) characterized by the presence of microvilli expands on $\mathrm{CCl}_{4}$ treatment (arrows). JCs (junctional complexes) indicate zonula occludens and zonula adherens. B: Quantification of the $\mathrm{BC}$ lumen size in $\mathbf{A}$ by measuring from one end to the opposite end of the lumen side of the junctional complexes (JCs; arrows). The $B C$ lumen size dilates in rat livers at 2 or 6 hours after $\mathrm{CCl}_{4}$ administration. Lumen expansion is significantly different between control ( 0 hours) and after 2 and 6 hours of $\mathrm{CCl}_{4}$ treatment. Data are expressed as means \pm SD. $n=38$ lumens at 0 hours, $n=14$ lumens at 2 hours, and $n=24$ lumens at 6 hours. ${ }^{* *} P<0.01,{ }^{* *} P<0.005$ versus $C$ by Welch's $t$-test. Scale bar $=1 \mu \mathrm{m}$.

TJs. ${ }^{1-4}$ Ultrastructural analysis revealed that TJs were restricted to a narrow band of membrane on either side of a bile capillary (Figure $2 \mathrm{~A}$ ). In contrast, $\mathrm{CCl}_{4}$-treated hepatocytes had disrupted contact points of TJs and expansion of the intercellular space (Figure 2A). Similar data were reported, revealing that $\mathrm{CCl}_{4}$ treatment resulted in the progressive loosening and fragmentation of the junctional meshwork. ${ }^{17}$

Furthermore, the bile canalicular lumen size, but not the junctional structure length (data not shown), was expanded in $\mathrm{CCl}_{4}$-treated rat livers (Figure 2). The lumen expansion was significantly different between control (0 hours) and after 2 or 6 hours of $\mathrm{CCl}_{4}$ treatment (control, $1.10 \pm 0.32 \mu \mathrm{m} ; 2$ hours, $1.62 \pm 0.64 \mu \mathrm{m}$; 
6 hours, $2.13 \pm 1.07 \mu \mathrm{m}$ ) (Figure 2B). These data suggest that $\mathrm{CCl}_{4}$-induced oxidative stress caused a disturbance of hepatocyte junctional structures and expansion of the bile canaliculi lumen.

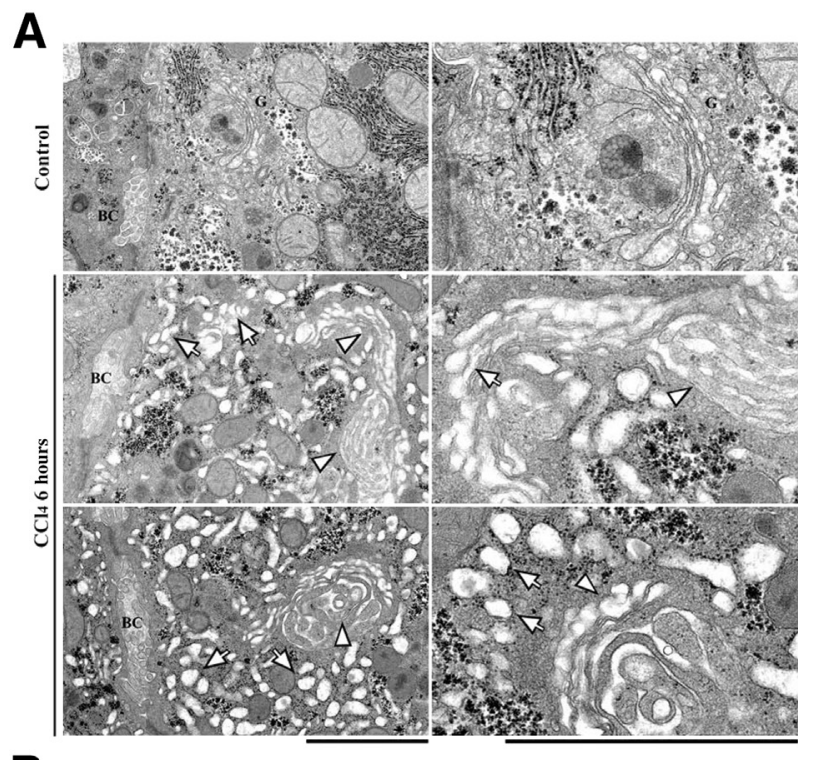

B
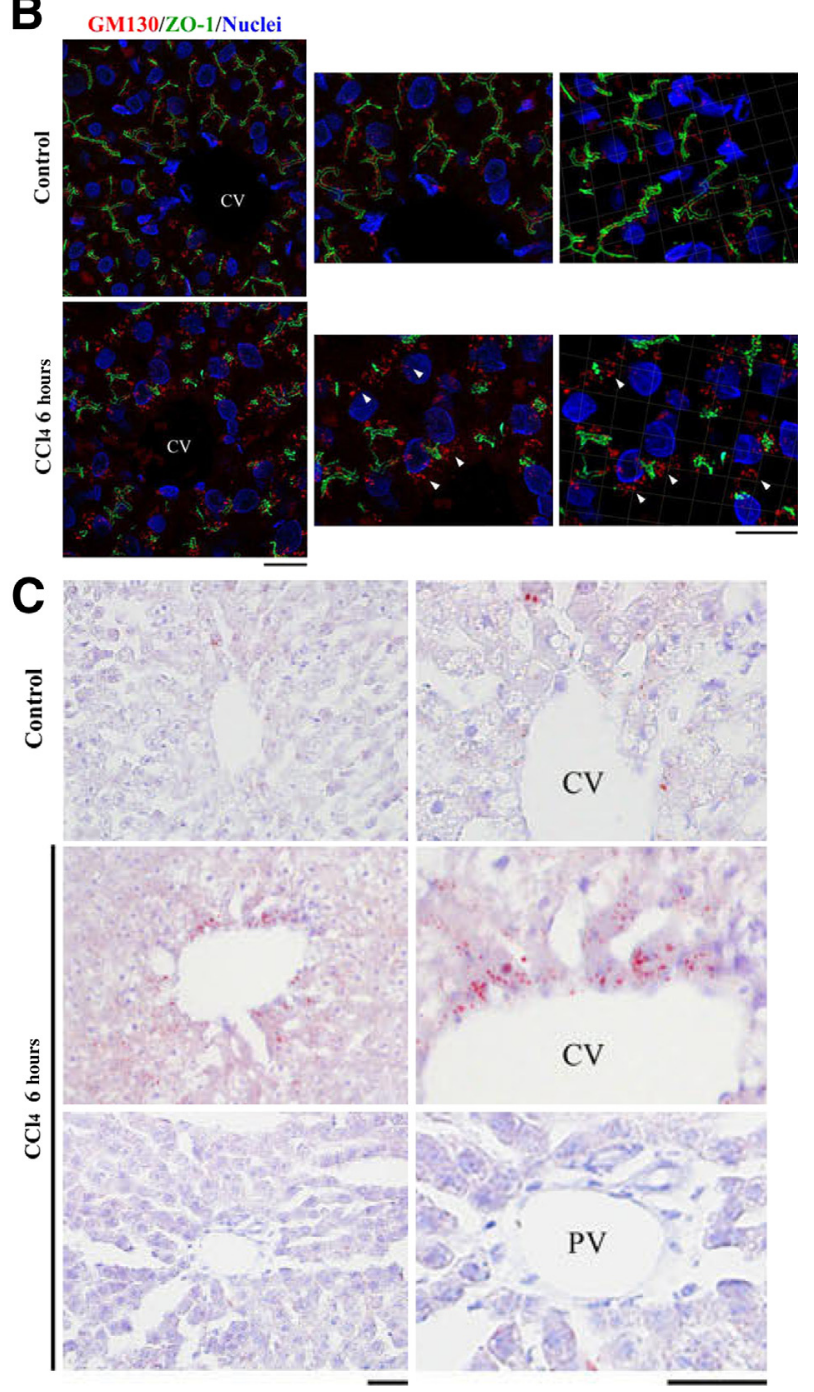

Oxidative Stress-Induced Hepatotoxicity Results in Disturbance of Cell Polarity

The structures of the endoplasmic reticulum, plasma membrane, and Golgi apparatus of the liver parenchymal cell are strikingly altered after administration of a single oral dose of carbon tetrachloride to rats. ${ }^{21}$ The Golgi apparatus has an important role in vesicle transport and the maintenance of cell polarity. ${ }^{9,22,23}$ An increased number of unattached ribosomes were found amid altered granular endoplasmic reticulum in $\mathrm{CCl}_{4}$-treated hepatocytes (Figure 3A). Furthermore, the Golgi apparatus was irregularly dilated in $\mathrm{CCl}_{4}$-treated cells of the centrilobular zone, and swollen Golgi vacuoles were observed (Figure 3A). These changes, first seen in cells of the centrilobular zone within 2 hours after $\mathrm{CCl}_{4}$ administration, were progressive to 6 hours (Figure 2A). The Golgi marker, GM130, was asymmetrically localized above the luminal side of the nuclei adjacent to ZO-1-positive cell-cell junctions (Figure 3B). In contrast, disassembly of Golgi bodies was observed in $\mathrm{CCl}_{4}$-treated hepatocytes (Figure 3B). Furthermore, staining for TGN38, a trans-Golgi networkspecific protein, was significantly decreased in the centrilobular zone of $\mathrm{CCl}_{4}$-treated rats (Supplemental Figure S3A). The Golgi apparatus also serves as a station for protein sorting and lipid transport. ${ }^{18,22,24}$ A marked increase in lipid accumulation was observed in $\mathrm{CCl}_{4}$-treated rat livers in the centrilobular zone (Figure $3 \mathrm{C}$ and Supplemental Figure S1B). In the liver, P-glycoprotein (MDR1), the product of a multidrug-resistance gene $(A B C B 1)$, is found exclusively on the biliary canalicular front of hepatocytes and on the apical surface of epithelial cells. ${ }^{2}$ Supplemental Figure S3B shows P-glycoprotein staining on the apical surface of hepatocytes in control rats. Consistent with the apical microvilli formation data (Figures 2 and 3), no significant difference was found between control and $\mathrm{CCl}_{4}$ treated rats. However, both bile canalicular lumen morphology (size) and Golgi orientation were disturbed by $\mathrm{CCl}_{4}$ treatment. These results provided support that $\mathrm{CCl}_{4}$ treatment induced impairment of vesicle transport and apicobasal cell polarity in rat hepatocytes.

Figure 3 Carbon tetrachloride $\left(\mathrm{CCl}_{4}\right)$ treatment induces a disturbance of Golgi morphology. A: Transmission electron micrographs show the cytoplasmic matrix of hepatocytes after administration of $\mathrm{CCl}_{4}$ to an animal. The membrane of the granular endoplasmic reticulum is sparsely and irregularly lined by ribosomes. Furthermore, components of the Golgi apparatus (G) are irregularly swollen (arrowheads), and the number of dilated granules (arrows) increases. BC indicates bile canaliculus. B: Rat livers were immunostained for GM130 (red), Z0-1 (green), and nuclei (blue). In control (0 hours) livers, the cis-Golgi marker GM130 is asymmetrically distributed above the bile canaliculus side of the nuclei but not in $\mathrm{CCl}_{4}$-treated livers (6 hours) (arrowheads). Confocal stack images are presented. Right panels are IMAEIS images (Carl Zeiss). CV indicates centrilobular vein. C: Frozen sections of livers were fixed and stained for lipid by oil red 0 staining. $\mathrm{CCl}_{4}$-treated liver ( 2 and 6 hours) sections reveal extensive fatty degeneration of hepatocytes in the centrilobular zone (red signals). Scale bars and grid scale: $2 \mu \mathrm{m}(\mathbf{A}) ; 20 \mu \mathrm{m}$ (B); $50 \mu \mathrm{m}$ (C). BC, bile canaliculus; CV, centrilobular vein; $\mathrm{PV}$, portal vein. 

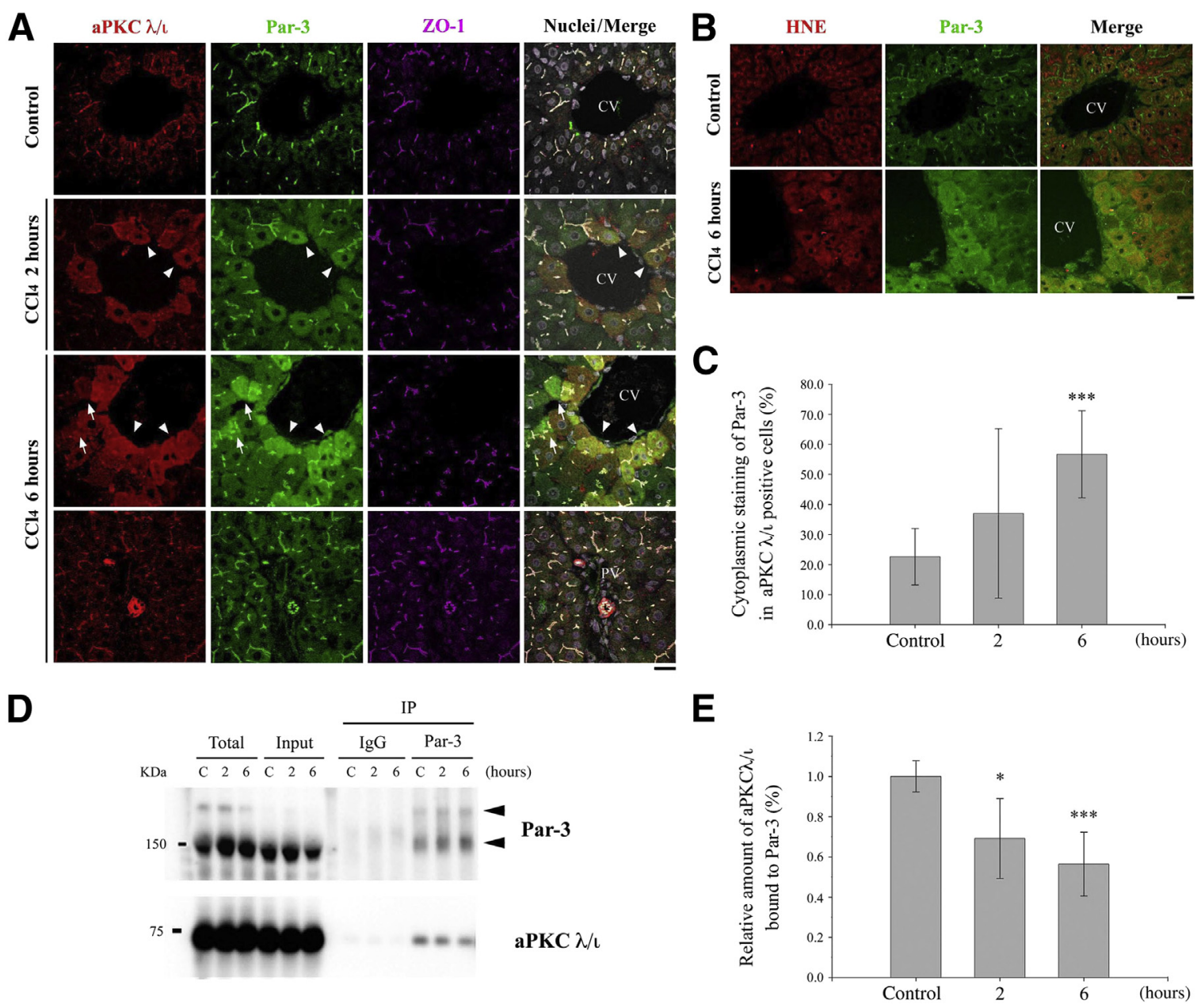

Figure 4 Formation of Par complex is essential for the maintenance of hepatocyte polarity. A: Control (0 hours) or carbon tetrachloride $\left(\mathrm{CCl}_{4}\right)-$ treated ( 2 and 6 hours) rat livers were immunostained for atypical protein kinase C (aPKC) $\lambda / \iota$ (red), Par-3 (green), Z0-1 (magenta), and nuclei (white). Note that in $\mathrm{CCl}_{4}$-treated liver, localization of aPKC $\lambda / \mathrm{l}$ and Par-3 is disrupted at Z0-1-positive cell-cell contact sites and subsequently relocalized to the cytoplasm (arrowheads indicate co-localization of aPKC and Par-3). Arrows indicate differential localization of aPKC $\lambda / \mathrm{I}$ and Par-3. CV indicates centrilobular vein; PV, portal vein. B: At 6 hours after $\mathrm{CCl}_{4}$ treatment of rat liver, Par-3 (green) strongly localizes to the cytoplasm in anti-4-hydroxy-2-nonenal (HNE) -positive hepatocytes (red). Confocal stack sections are presented in A and B. C: Quantification of the percentage of cells with cytoplasmic co-localization of aPKC $\lambda / \mathbf{\imath}$ and Par-3. The amount of cytoplasmic staining of Par-3 in aPKC $\lambda / \mathrm{l}$-positive cells was increased with $\mathrm{CCl}_{4}$ treatment. D: Control or $\mathrm{CCl}_{4}$-treated (2 and 6 hours) livers were lyzed with lysis buffer (total). The supernatant fraction (input) was subjected to immunoprecipitation (IP) with anti-Par-3 antibody, and precipitated proteins were analyzed by Western blot (IP). E: Quantification of the amount of aPKC $\lambda / \mathrm{I}$ in the IP fraction shows significant decrease with $\mathrm{CCl}_{4}$ treatment. Data are presented as means $\pm \mathrm{SD}(\mathbf{C}$ and $\mathbf{E}) . n=4(\mathbf{C}) ; n=5(\mathbf{E}) .{ }^{*} P<0.05,{ }^{* *} P<0.005$ versus control by Student's $t$-test. Scale bar $=20 \mu \mathrm{m}$.

Interaction between Par-3 and aPKC Is Required for the Maintenance of Hepatocyte Polarity

The Par complex plays a crucial role in TJ formation during epithelial cell polarization and epithelial tissue morphogenesis. ${ }^{8,15}$ We found that Par-3 and aPKC $\lambda /$ l localized to ZO1 -positive cell-cell junctional regions in control rat livers (Figure 4, A and B). These localizations strikingly changed to the cytoplasm in the centrilobular zone after $\mathrm{CCl}_{4}$ treatment (Figure 4A). However, the localization of ZO-1, Par-3, and aPKC $\lambda / \mathrm{t}$ was not affected in the portal area of hepatocytes after $\mathrm{CCl}_{4}$ administration. The amount of cytoplasmic co-staining of Par-3 and aPKC $\lambda / \mathrm{t}$ was significantly increased in the centrilobular zone at 6 hours after $\mathrm{CCl}_{4}$ administration (control, $22.6 \pm 9.4 ; 2$ hours, $36.9 \pm 28.2 ; 6$ hours, $56.7 \pm 14.5$ ) (Figure 4, A and C). To examine whether the interaction between aPKC and Par-3 is essential for maintaining hepatocyte junction and polarity, we analyzed the binding ability of Par-3 to aPKC in $\mathrm{CCl}_{4}$-treated rat liver by immunoprecipitation assay. Using a co-sedimentation analysis, we found that binding of Par-3 to aPKC $\lambda / \mathrm{\iota}$ was severely impaired in $\mathrm{CCl}_{4}$ treated rat livers (Figure 4, D and E). These data indicated that cytoplasmic Par-3 did not bind to aPKC $\lambda / \mathrm{s}$ (Figure 4A). Our findings suggested that the interaction between aPKC and Par-3 was necessary to maintain localization and hepatocyte junctional structures.

\section{0xidative Stress Inhibits Interaction between Par-3 and aPKC through Aberrant aPKC Activation}

It was previously reported that aPKC phosphorylates Ser827 on Par-3, which reduces the stable interaction of Par-3-aPKC. ${ }^{14}$ 


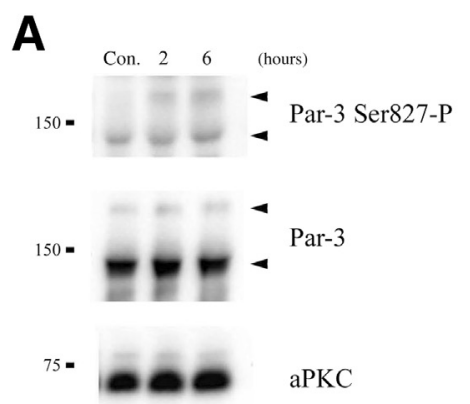

C

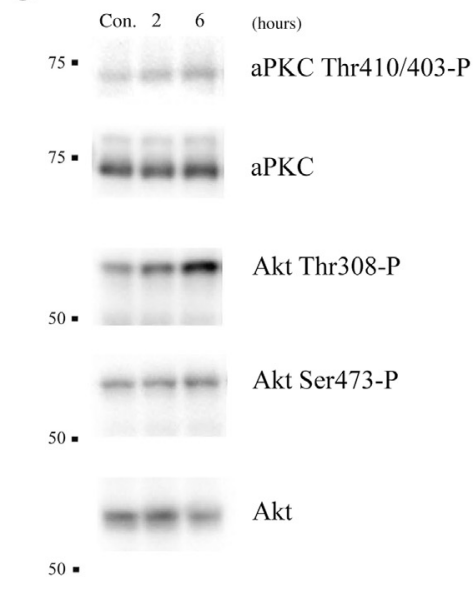

E

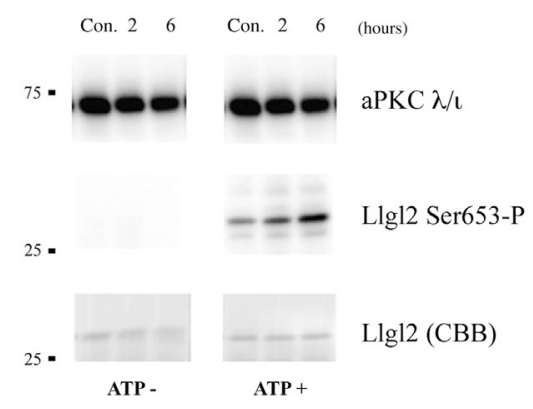

B

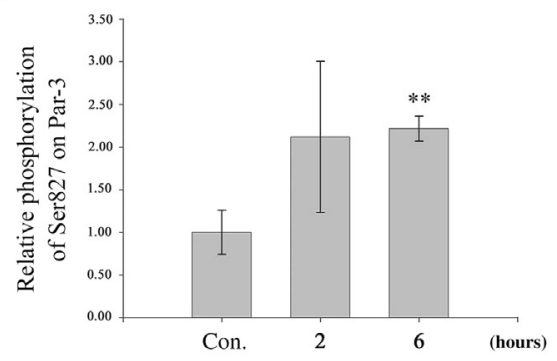

D

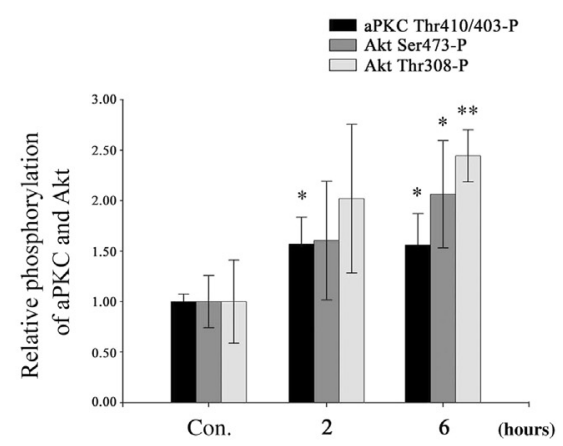

$\mathbf{F}$

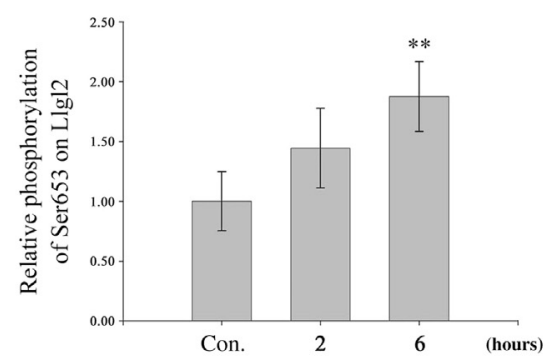

Figure 5 Carbon tetrachloride $\left(\mathrm{CCl}_{4}\right)_{-}$ mediated oxidative stress induces up-regulation of Par-3-Ser827 phosphorylation and atypical protein kinase $\mathrm{C}(\mathrm{aPKC})$ kinase activation. A: Western blot analysis of Par-3 phosphorylation status with antiphospho-Par-3 Ser827 antibody and anti-Par-3 antibody. B: Relative Ser827 phosphorylation on Par-3 is normalized to nonphosphorylated Par-3. C: Western blot analysis of control (Con.) (0 hours) or $\mathrm{CCl}_{4}$-treated (2 and 6 hours) rat livers with antibodies against indicated proteins. D: The phosphorylation levels of aPKC $/ \lambda$ Thr410/403, Akt-Thr308, and Akt-Ser437 were quantified and found to be significantly increased in $\mathrm{CCl}_{4}$-treated rat liver. E: Con. (0 hours) and $\mathrm{CCl}_{4}$-treated (2 and 6 hours) rat livers were subjected to immunoprecipitation (IP) with the anti-aPKC antibody or control IgG. The IPs were incubated in the presence of glutathione S-transferase-Llgl2 peptide with ATP and detected by using anti-phospho-Llgl2 Ser653 antibody together with anti-aPKC $\lambda / \mathrm{L}$ antibody. F: Quantification of the results in E. Phosphorylation of Llgl2 is significantly increased at 6 hours after $\mathrm{CCl}_{4}$ treatment. Data are presented as means \pm SD $(\mathbf{B}, \mathbf{D}$, and $\mathbf{F}) . n=4(\mathbf{B}) ; n=3$ to 5 (D and $\mathbf{F}) .{ }^{*} P<0.05$, ${ }^{*} P<0.01$ versus Con. by Student's $t$-test.
Phosphorylation of Par-3 was enhanced approximately 2.5-fold within 6 hours after $\mathrm{CCl}_{4}$ treatment (control: $1.00 \pm 0.26 ; 2$ hours: $2.12 \pm 0.89 ; 6$ hours: $2.22 \pm 0.15$ ) (Figure 5, A and B). PI3-kinase produces phosphatidylinositol (3,4,5)-triphosphate $\left[\operatorname{PtdIns}(3,4,5) \mathrm{P}_{3}\right]$, and the latter activates phosphoinositide-dependent protein kinase-1 (PDK1), which potently activates aPKC and Akt. $^{25,26}$ PDK1 phosphorylates aPKC $\zeta / \lambda$ on Thr410/403 and activates it. We found that the phosphorylation level of Thr410/403 on aPKC $\zeta / \lambda$ increased with $\mathrm{CCl}_{4}$ treatment (control: $1.00 \pm 0.08 ; 2$ hours: $1.57 \pm 0.26$; 6 hours: $1.56 \pm 0.31$ ) (Figure 5, C and D). Furthermore, both AktThr308 and Akt-Ser473 phosphorylations were significantly elevated in $\mathrm{CCl}_{4}$-treated liver (control, $1.00 \pm 0.26$; 2 hours, $1.60 \pm 0.59 ; 6$ hours, $2.06 \pm 0.53$ ) (Figure 5, C and D). The PI3-kinase signaling pathway is activated under oxidative stress. ${ }^{27}$ Our data support the hypothesis that aberrant activation of aPKC is induced by oxidative stress-mediated activation of PI3-kinase signaling. However, the activation of aPKC in $\mathrm{CCl}_{4}$-treated rats has not been clarified. A glutathione $S$-transferase fusion protein with amino acid sequence 636 to 666 of human $\operatorname{Llgl} 2$ (Llg12 peptide) is phosphorylated by purified aPKC from cultured cells in vitro. ${ }^{15}$ After $\mathrm{CCl}_{4}$ treatment, liver lysates were subjected to immunoprecipitation with anti-aPKC antibody, and then an in vitro immune complex kinase assay was performed. We revealed that phosphorylation of the $\operatorname{Llgl} 2$ peptide was markedly increased after $\mathrm{CCl}_{4}$ treatment (control, $1.00 \pm 0.25 ; 2$ hours, $1.44 \pm 0.33 ; 6$ hours, $1.88 \pm 0.29$ ) (Figure 5, E and F). Aberrant activation of aPKC caused hyperphosphorylation of Par-3 and led to the dissociation of Par-3-aPKC interaction. These results suggested that aPKC overactivation induced a disturbance in hepatocyte polarity. 

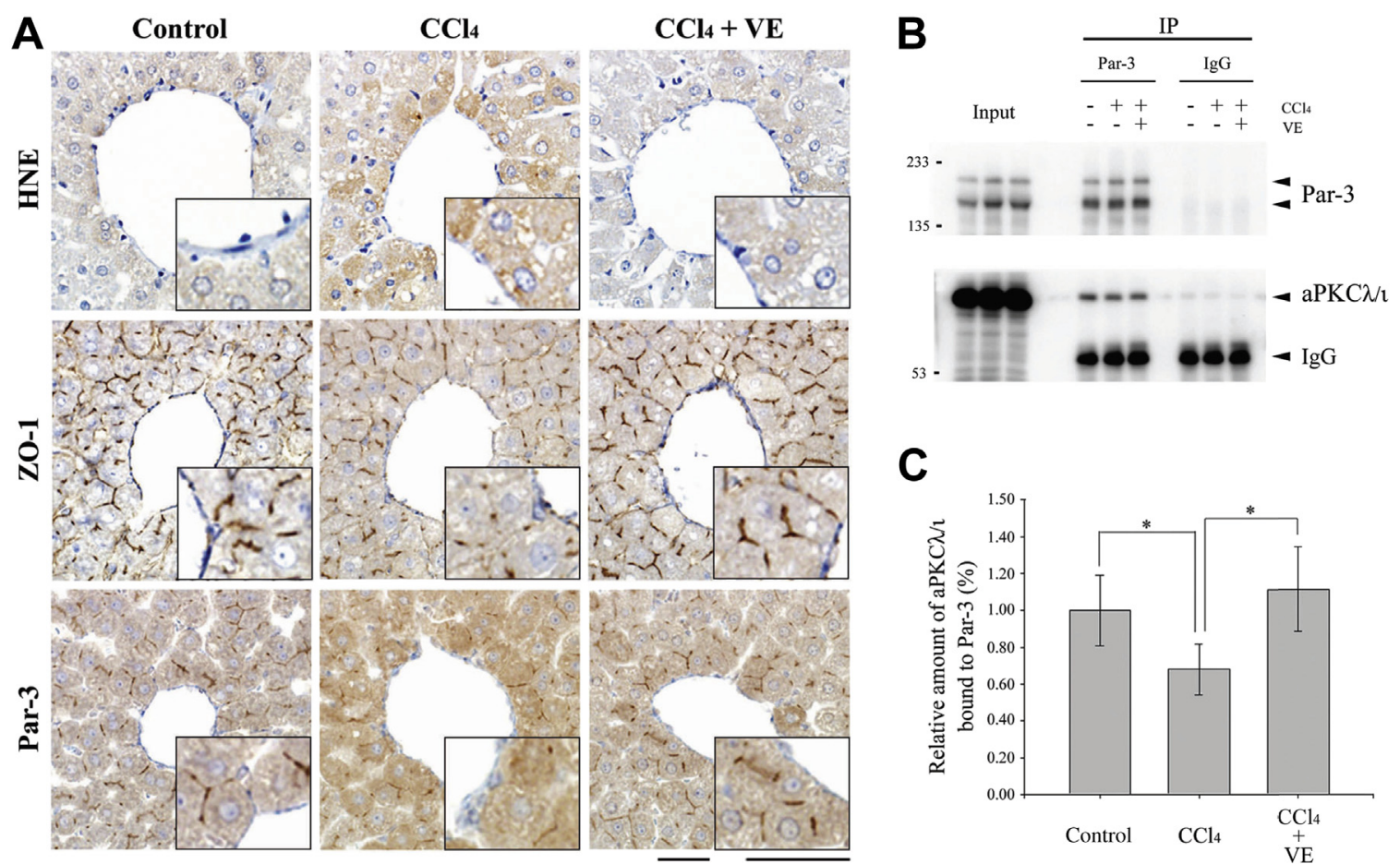

Figure 6 Vitamin E prevents carbon tetrachloride $\left(\mathrm{CCl}_{4}\right)$-induced disassembly of tight junctions (TJs) and Par-3-atypical protein kinase $\mathrm{C}$ (aPKC) interaction. A: Control and $\mathrm{CCl}_{4}$-treated rat livers with $\left(\mathrm{CCl}_{4}+\mathrm{VE}\right)$ or without $\left(\mathrm{CCl}_{4}\right)$ vitamin E were immunostained for anti-4-hydroxy-2-nonenal ( $\left.\mathrm{HNE}\right)$, Z0-1, and Par-3. HNE staining decreases in vitamin E-treated livers. In addition, vitamin E partially prevents $\mathrm{CCl}_{4}$-induced disassembly of Z0-1 and reduces Par-3 staining. B: Livers from vehicle-administered and $\mathrm{CCl}_{4}$-treated rats with or without vitamin $\mathrm{E}$ were harvested 6 hours after administration, supernatant fraction (input), and subjected to immunoprecipitation (IP) using antibody against Par-3. Precipitated proteins were analyzed by Western blot. C: Quantification of the amount of aPKC $\lambda / \mathrm{l}$ in the IP fraction shows significant decrease with $\mathrm{CCl}_{4}$ treatment $\left(\mathrm{CCl}_{4}\right)$, but not with vitamin $\mathrm{E}$ injection $\left(\mathrm{CCl}_{4}+\mathrm{VE}\right)$. Data are presented as means \pm SD. $n=3$ to 4 . ${ }^{*} P<0.05$ versus control by Student's $t$-test. Scale bar $=40 \mu \mathrm{m}$. IP, immunoprecipitation.

\section{Vitamin E Prohibits $\mathrm{CCl}_{4}$-Induced Par-3-aPKC Dissociation and aPKC Activation}

Vitamin $E$ is one of the most important natural antioxidants that suppress the peroxidation of membrane lipids by $\mathrm{CCl}_{4} \cdot{ }^{28}$ In $\mathrm{CCl}_{4}$-treated rat liver, Par-3 and aPKC were delocalized to the cytoplasm from ZO-1-positive cell-cell junctions (Figure 4A and Figure 6A). Vitamin E prevented HNE accumulation by $\mathrm{CCl}_{4}$ treatment (Figure 6A). Moreover, vitamin $\mathrm{E}$ prohibited both $\mathrm{CCl}_{4}$-induced disruption of ZO-1 and Par-3 cytoplasmic relocalization (Figure 6A). In addition, we analyzed the interaction between Par-3 and aPKC in rat liver with both $\mathrm{CCl}_{4}$ and vitamin $\mathrm{E}$ treatments. Immunoprecipitation analysis revealed that vitamin $\mathrm{E}$ significantly prohibited $\mathrm{CCl}_{4}$ induced dissociation of Par-3-aPKC binding (control, $1.00 \pm 0.19 ; \mathrm{CCl}_{4}, 0.68 \pm 0.14 ; \mathrm{CCl}_{4}+$ vitamin $\mathrm{E}$, $1.12 \pm 0.23$ ) (Figure 6, B and C). These data suggest that the inhibition of the polarity-regulating Par complex is involved in hepatic injury through aberrant aPKC activation by $\mathrm{CCl}_{4}$-mediated oxidative stress in rat liver.

\section{Discussion}

We found that $\mathrm{CCl}_{4}$-induced oxidative stress results in the disassembly of junctional structures. $\mathrm{CCl}_{4}$ induces a phenotype similar to hepatic cirrhosis and cholestasis in rat liver. ${ }^{17-19}$ In several clinical forms of cholestasis and in cholestatic models, distinct functional and morphologic alterations of TJs have been described in hepatocytes. ${ }^{1-5}$ The functional integrity of TJs is crucial in preventing paracellular leakage of bile constituents. However, the molecular mechanisms of disturbance of TJs remain obscure. The Par-3-aPKC complex plays a crucial role in $\mathrm{TJ}$ formation during epithelial cell polarization and epithelial tissue morphogenesis. ${ }^{8,15} \mathrm{We}$ revealed that the localization of Par-3 and aPKC to the cell junctional region was inhibited by $\mathrm{CCl}_{4}$ treatment. In addition, the interaction between Par-3 and aPKC (Par-3-aPKC complex formation) was decreased in $\mathrm{CCl}_{4}$-treated liver (Figure 4). Par-3 is a scaffold protein that stabilizes localization of aPKC to cell-cell contact regions. ${ }^{8,29,30}$ Par-3 knockdown facilitates the disassembly of TJs and redistribution of apical proteins to intracellular regions. ${ }^{31}$ In contrast, overexpression of Par-3, which led to high expression of Par-3 at $\mathrm{TJs},{ }^{32}$ induced the retention of peripheral apical proteins in depolarized epithelial cells. ${ }^{31}$ These results suggested that Par-3 plays a negative role in the disassembly of apical junctional complex in epithelial cells.

Decreased or even absent expression of specific hepatocellular transport proteins has been found in several clinical forms and experimental models of cholestasis. ${ }^{2,33}$ Targeting membrane components, transcytosis, and canalicular exocytosis of vesicles are also disrupted during cholestasis, 
A

$\mathrm{CCl}_{4}$-induced oxidative stress

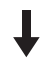

Aberrant aPKC activation

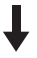

Phosphorylation of Ser827 on Par-3

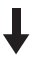

Dissociation of Par-3-aPKC interaction

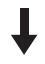

Disassembly of junctions (TJs) \&

Fragmentation of Golgi

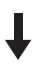

Disturbance of cell polarity

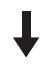

Bile canalicular lumen expansion

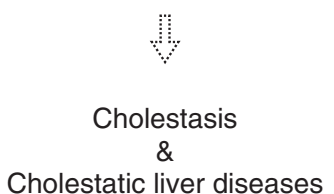

B Polarized cell (Hepatocyte)

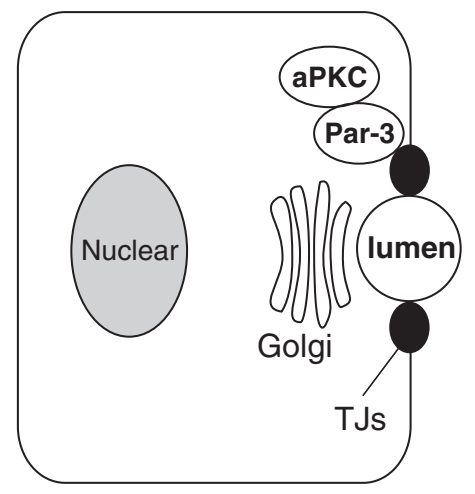

C

Disturbance of cell polarity

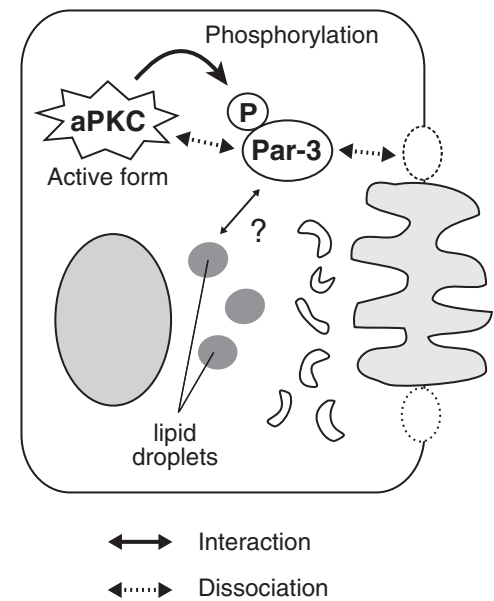

Figure 7 Model for the mechanism of oxidative stress-induced disturbance of cell polarity. A: Our findings suggest that carbon tetrachloride $\left(\mathrm{CCl}_{4}\right)$-induced oxidative stress causes aberrant atypical protein kinase $\mathrm{C}(\mathrm{aPKC})$ activation, which leads to hyperphosphorylation of Ser827 on Par-3 and dissociation of the PAR-3-aPKC interaction. This results in disassembly of junctions, fragmentation of the Golgi apparatus, and disturbance of cell polarity and bile canalicular lumen expansion. Ultimately, these alterations promote the development of cholestasis and cholestatic liver diseases. B: On polarized hepatocytes, the polarity proteins, Par-3 and aPKC, localize to Z0-1positive junctions. Golgi apparatus is asymmetrically distributed above the canalicular luminal side of the nuclei. C: Because of the direct interaction of Par-3 with phospholipids, the cytoplasmic accumulation of which is induced by $\mathrm{CCL}_{4}$, Par-3 and $\mathrm{aPKC}$ binding is inhibited and their localization to tight junctions is lost, resulting in disassembly of junctional structures and disturbance of cell polarity. resulting in the retention of apical transporters on the basolateral surface of hepatocytes and a delay in vesicle transport to the bile canaliculi. ${ }^{2,34-36} \mathrm{We}$ also found that $\mathrm{CCl}_{4}$ treatment in rat resulted in Golgi disorientation and disassembly of the trans-Golgi network (Figure 3 and Supplemental Figure S3). In addition, ultrastructural analysis revealed that the Golgi apparatus underwent irregular expansion or tabulation (Figure 3). This altered structure is similar to labyrinthine tubular aggregates but differs from smooth endoplasmic reticulum. ${ }^{37} \mathrm{CCl}_{4}$ is converted to a trichloromethyl $\left(\mathrm{CCl}_{3}\right)$ radical by the cytochrome $\mathrm{P} 450$ system. This radical is very reactive and quenched by adjacent lipids, resulting in lipid peroxidation or binding covalently to membrane proteins and lipids. ${ }^{38,39}$ In general, the $\mathrm{CCl}_{3}$ radical reacts with polysomes, causing their disaggregation, and with both endoplasmic reticulum membrane and plasmalemma, distorting their functions and structures. ${ }^{37-39}$ $\mathrm{CCl}_{4}$-induced disturbance of hepatocyte polarity can be caused by altered Golgi structure or disorganized vesicle transport. The orientation of the centrosome contributes to overall cell polarity by positioning both the Golgi and the endocytic recycling compartment. Par-3 is required for centrosome orientation and centration by regulating microtubule dynamics. ${ }^{40}$ Moreover, Par-3 associates with dynein and a small amount of aPKC. aPKC also interacts with dynein to maintain the microtubule-organizing center at the cell centroid. $^{41}$ These results suggested that the interaction between Par-3 and aPKC may be necessary for regulating cell polarity through Golgi orientation or other mechanisms (Figure 7).

We revealed that localization of the cell polarity-regulating proteins Par-3 and aPKC to the cell junctional region was inhibited by $\mathrm{CCl}_{4}$ treatment. Importantly, biochemical analysis revealed that the Par-3-aPKC complex was markedly decreased in $\mathrm{CCl}_{4}$-treated rat livers. Furthermore, phosphorylation of Ser827 on Par-3 was increased with elevation of aPKC activity. It was reported that aPKC phosphorylates Ser827 on Par-3, which reduces the stable interaction of Par-3-aPKC. ${ }^{14}$

aPKC is activated by direct binding of PtdIns $(3,4,5)$ to its cysteine-rich domain. ${ }^{26}$ PI3-kinase signaling is characterized by the stimulated production of the second messenger, PtdIns(3,4,5) $\mathrm{P}_{3}$. PtdIns $(3,4,5) \mathrm{P}_{3}$ activates PDK1, which 
potently activates aPKC and Akt. ${ }^{25,26}$ We revealed that the phosphorylation levels of aPKC and Akt were significantly increased by $\mathrm{CCl}_{4}$ treatment (Figure 5). These data indicated that aberrant activation of aPKC in $\mathrm{CCl}_{4}$-treated liver was induced by PI3-kinase signaling.

The activity of PTEN, the $\operatorname{PtdIns}(3,4,5) \mathrm{P}_{3}$ phosphatase, is inhibited by oxidative stress, which causes an increase in cellular PtdIns $(3,4,5) \mathrm{P}_{3}$ levels. ${ }^{27}$ This suggests that oxidative stress is able to activate PI3-kinase-dependent signaling. Thus, $\mathrm{CCl}_{4}$-mediated activation of PI3-kinase signaling might activate aPKC.

Ultrastructural analysis revealed that the bile canalicular lumen was extended in $\mathrm{CCl}_{4}$-treated rat livers (Figure 2). In freeze-fracture replicas, analysis revealed that extrahepatic cholestasis is observed in the dilatation of the bile canaliculi space. $^{4}$ aPKC kinase activation induced expansion of the apical lumen in cultured epithelial cells through enhanced de novo apical exocytosis. ${ }^{42}$ We previously found that Par-3 knockdown results in a delay of apical protein carrier vesicle transport and leads eventually to delocalization of the apical

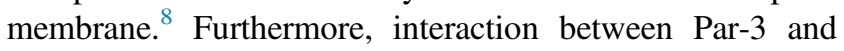
aPKC is required for targeting of these protein carrier vesicles to primordial junction structures and normal apical domain development, such as organized lumen formation. ${ }^{8}$ Par-3 plays a critical role in regulating centrosome orientation for bile canaliculus formation, but not its maintenance, in cultured rat hepatocytes. ${ }^{11}$ In this study, we found that Par-3-aPKC may play a crucial role in the maintenance of the bile canalicular lumen. This finding would provide novel insights into the understanding of maintenance and disturbance of the bile canalicular lumen. In $\mathrm{CCl}_{4}$-treated hepatocytes, the apical protein P-glycoprotein was localized to the bile canaliculus (Supplemental Figure S3A). In addition, ultrastructural analysis revealed that apical microvilli formation was not altered (Figures 2 and 3). These data suggested that the apical domain was not affected. However, knockdown of Par-3 in epithelial cells revealed significant impairment of apical domain development. $^{8}$

$\mathrm{CCl}_{4}$ treatment induces accumulation of lipid-like material and secondary lysosomes in hepatocytes. ${ }^{38,39}$ Par-3 and aPKC bind directly to phosphatidylinositol lipids. ${ }^{26,43,44}$ Par-3 and aPKC may interact with $\mathrm{CCl}_{4}$-induced lipid droplets within hepatocytes and translocate from TJs to the cytoplasm. Thus, it is possible that Par-3 and aPKC are attracted to the accumulated lipids in the cytoplasm (Figure 7). We found that $\mathrm{CCl}_{4}$-mediated bile canalicular lumen expansion was caused by aberrant activation of aPKC. Administration of vitamin $\mathrm{E}$ effectively prohibited $\mathrm{CCl}_{4^{-}}$ induced cytoplasmic localization of Par-3 and aPKC in rat liver. In fact, vitamin $\mathrm{E}$ blocked $\mathrm{CCl}_{4}$-induced increase in 4-hydroxy2-nonenal adducts and preserved liver morphology (Figure 6). Our findings identified a novel effect of vitamin $\mathrm{E}$ in oxidative stress-mediated cell injury, but further analysis is needed.

Our results suggested that $\mathrm{CCl}_{4}$-mediated oxidative stress disturbed Par-3-aPKC interaction and led to a defect in hepatocyte polarity by aberrant activation of aPKC, indicating a link between the disturbance of cell polarity and cholestasis progression by oxidative stress. Further studies will clarify the molecular mechanisms underlying primary biliary cirrhosis, primary sclerosing cholangitis, and progressive intrahepatic cholestasis.

\section{Acknowledgment}

We thank Johbu Itoh for technical assistance with confocal laser microscopy.

\section{Supplemental Data}

Supplemental material for this article can be found at http://dx.doi.org/10.1016/j.ajpath.2014.12.015.

\section{References}

1. Kojima T, Yamamoto T, Murata M, Chiba H, Kokai Y, Sawada N: Regulation of the blood-biliary barrier: interaction between gap and tight junctions in hepatocytes. Med Electron Microsc 2003, 36: $157-164$

2. Trauner M, Meier PJ, Boyer JL: Molecular pathogenesis of cholestasis. N Engl J Med 1998, 339:1217-1227

3. Ludwig J, Barham SS, LaRusso NF, Elveback LR, Wiesner RH, McCall JT: Morphologic features of chronic hepatitis associated with primary sclerosing cholangitis and chronic ulcerative colitis. Hepatology 1981, 1:632-640

4. Robenek H, Herwig J, Themann H: The morphologic characteristics of intercellular junctions between normal human liver cells and cells from patients with extrahepatic cholestasis. Am J Pathol 1980, 100:93-114

5. Sakisaka S, Kawaguchi T, Taniguchi E, Hanada S, Sasatomi K, Koga H, Harada M, Kimura R, Sata M, Sawada N, Mori M, Todo S, Kurohiji T: Alterations in tight junctions differ between primary biliary cirrhosis and primary sclerosing cholangitis. Hepatology 2001, 33: $1460-1468$

6. Suzuki A, Ohno S: The PAR-aPKC system: lessons in polarity. J Cell Sci 2006, 119:979-987

7. Martin-Belmonte F, Perez-Moreno M: Epithelial cell polarity, stem cells and cancer. Nat Rev Cancer 2012, 12:23-38

8. Horikoshi Y, Suzuki A, Yamanaka T, Sasaki K, Mizuno K, Sawada H, Yonemura S, Ohno S: Interaction between PAR-3 and the aPKC-PAR6 complex is indispensable for apical domain development of epithelial cells. J Cell Sci 2009, 122:1595-1606

9. Datta A, Bryant DM, Mostov KE: Molecular regulation of lumen morphogenesis. Curr Biol 2011, 21:R126-136

10. Wapenaar MC, Monsuur AJ, van Bodegraven AA, Weersma RK, Bevova MR, Linskens RK, Howdle P, Holmes G, Mulder CJ, Dijkstra G, van Heel DA, Wijmenga C: Associations with tight junction genes PARD3 and MAGI2 in Dutch patients point to a common barrier defect for coeliac disease and ulcerative colitis. Gut 2008, 57 : 463-467

11. Wang T, Yanger K, Stanger BZ, Cassio D, Bi E: Cytokinesis defines a spatial landmark for hepatocyte polarization and apical lumen formation. J Cell Sci 2014, 127:2483-2492

12. Hirose T, Satoh D, Kurihara H, Kusaka C, Hirose H, Akimoto K, Matsusaka T, Ichikawa I, Noda T, Ohno S: An essential role of the universal polarity protein, aPKClambda, on the maintenance of podocyte slit diaphragms. PLoS One 2009, 4:e4194

13. Yang SM, Hua KF, Lin YC, Chen A, Chang JM, Kuoping Chao L, Ho CL, Ka SM: Citral is renoprotective for focal segmental 
glomerulosclerosis by inhibiting oxidative stress and apoptosis and activating Nrf2 pathway in mice. PLoS One 2013, 8:e74871

14. Nagai-Tamai Y, Mizuno K, Hirose T, Suzuki A, Ohno S: Regulated protein-protein interaction between aPKC and PAR-3 plays an essential role in the polarization of epithelial cells. Genes Cells 2002, 7: $1161-1171$

15. Yamanaka T, Horikoshi Y, Sugiyama Y, Ishiyama C, Suzuki A, Hirose T, Iwamatsu A, Shinohara A, Ohno S: Mammalian Lgl forms a protein complex with PAR- 6 and aPKC independently of PAR-3 to regulate epithelial cell polarity. Curr Biol 2003, 13: 734-743

16. Schnell SA, Staines WA, Wessendorf MW: Reduction of lipofuscinlike autofluorescence in fluorescently labeled tissue. J Histochem Cytochem 1999, 47:719-730

17. Robenek H, Themann H, Ott K: Carbon tetrachloride induced proliferation of tight junctions in the rat liver as revealed by freeze-fracturing. Eur J Cell Biol 1979, 20:62-70

18. Mehendale HM, Roth RA, Gandolfi AJ, Klaunig JE, Lemasters JJ, Curtis LR: Novel mechanisms in chemically induced hepatotoxicity. FASEB J 1994, 8:1285-1295

19. Koop DR: Oxidative and reductive metabolism by cytochrome P450 2E1. FASEB J 1992, 6:724-730

20. Kondo S, Toyokuni S, Iwasa $Y$, Tanaka T, Onodera H, Hiai H, Imamura M: Persistent oxidative stress in human colorectal carcinoma, but not in adenoma. Free Radic Biol Med 1999, 27:401-410

21. Reynolds ES: Liver parenchymal cell injury, I: initial alterations of the cell following poisoning with carbon tetrachloride. J Cell Biol 1963, 19:139-157

22. Orlando K, Guo W: Membrane organization and dynamics in cell polarity. Cold Spring Harb Perspect Biol 2009, 1:a001321

23. Etienne-Manneville S: Polarity proteins in migration and invasion. Oncogene 2008, 27:6970-6980

24. Keller P, Simons K: Post-Golgi biosynthetic trafficking. J Cell Sci 1997, 110(Pt 24):3001-3009

25. Chou MM, Hou W, Johnson J, Graham LK, Lee MH, Chen CS, Newton AC, Schaffhausen BS, Toker A: Regulation of protein kinase C zeta by PI 3-kinase and PDK-1. Curr Biol 1998, 8:1069-1077

26. Suzuki A, Akimoto K, Ohno S: Protein kinase C lambda/iota (PKClambda/iota): a PKC isotype essential for the development of multicellular organisms. J Biochem 2003, 133:9-16

27. Leslie NR, Bennett D, Lindsay YE, Stewart H, Gray A, Downes CP: Redox regulation of PI 3-kinase signalling via inactivation of PTEN. EMBO J 2003, 22:5501-5510

28. Toriumi K, Horikoshi Y, Yoshiyuki Osamura R, Yamamoto Y, Nakamura N, Takekoshi S: Carbon tetrachloride-induced hepatic injury through formation of oxidized diacylglycerol and activation of the PKC/NF-kappaB pathway. Lab Invest 2013, 93:218-229

29. Iden S, van Riel WE, Schafer R, Song JY, Hirose T, Ohno S, Collard JG: Tumor type-dependent function of the par3 polarity protein in skin tumorigenesis. Cancer Cell 2012, 22:389-403
30. Suzuki A, Ishiyama C, Hashiba K, Shimizu M, Ebnet K, Ohno S: aPKC kinase activity is required for the asymmetric differentiation of the premature junctional complex during epithelial cell polarization. $\mathrm{J}$ Cell Sci 2002, 115:3565-3573

31. Yamanaka T, Horikoshi Y, Izumi N, Suzuki A, Mizuno K, Ohno S: Lgl mediates apical domain disassembly by suppressing the PAR-3aPKC-PAR-6 complex to orient apical membrane polarity. J Cell Sci 2006, 119:2107-2118

32. Hirose T, Izumi Y, Nagashima Y, Tamai-Nagai Y, Kurihara H, Sakai T, Suzuki Y, Yamanaka T, Suzuki A, Mizuno K, Ohno S: Involvement of ASIP/PAR-3 in the promotion of epithelial tight junction formation. J Cell Sci 2002, 115:2485-2495

33. Trauner M, Meier PJ, Boyer JL: Molecular regulation of hepatocellular transport systems in cholestasis. J Hepatol 1999, 31:165-178

34. Trauner M, Nathanson MH, Rydberg SA, Koeppel TA, Gartung C, Sessa WC, Boyer JL: Endotoxin impairs biliary glutathione and HCO3- excretion and blocks the choleretic effect of nitric oxide in rat liver. Hepatology 1997, 25:1184-1191

35. Jones A, Selby PJ, Viner C, Hobbs S, Gore ME, McElwain TJ: Tumour necrosis factor, cholestatic jaundice, and chronic liver disease. Gut 1990, 31:938-939

36. Hoffman M, Mittelman A, Dworkin B, Rosenthal W, Beneck D, Gafney E, Arlin Z, Levitt D, Podack E: Severe intrahepatic cholestasis in patients treated with recombinant interleukin-2 and lymphokineactivated killer cells. J Cancer Res Clin Oncol 1989, 115:175-178

37. Sell DA, Reynolds ES: Liver parenchymal cell injury. 8. Lesions of membranous cellular components following iodoform. J Cell Biol 1969, 41:736-752

38. Smuckler EA: Structural and functional changes in acute liver injury. Environ Health Perspect 1976, 15:13-25

39. Bernacchi A, Myers R, Trump BF, Marzella L: Protection of hepatocytes with hyperoxia against carbon tetrachloride-induced injury. Toxicol Pathol 1984, 12:315-323

40. Schmoranzer J, Fawcett JP, Segura M, Tan S, Vallee RB, Pawson T, Gundersen GG: Par3 and dynein associate to regulate local microtubule dynamics and centrosome orientation during migration. Curr Biol 2009, 19:1065-1074

41. Gomes ER, Jani S, Gundersen GG: Nuclear movement regulated by Cdc42, MRCK, myosin, and actin flow establishes MTOC polarization in migrating cells. Cell 2005, 121:451-463

42. Yoshihama Y, Sasaki K, Horikoshi Y, Suzuki A, Ohtsuka T, Hakuno F, Takahashi S, Ohno S, Chida K: KIBRA suppresses apical exocytosis through inhibition of aPKC kinase activity in epithelial cells. Curr Biol 2011, 21:705-711

43. Krahn MP, Klopfenstein DR, Fischer N, Wodarz A: Membrane targeting of Bazooka/PAR-3 is mediated by direct binding to phosphoinositide lipids. Curr Biol 2010, 20:636-642

44. Horikoshi Y, Hamada S, Ohno S, Suetsugu S: Phosphoinositide binding by par-3 involved in par-3 localization. Cell Struct Funct 2011, 36:97-102 